Elsevier

HRR 00642

\title{
An energy-dependent step in aminoglycoside ototoxicity: Prevention of gentamicin ototoxicity during reduced endolymphatic potential
}

\author{
Akira Takada *, Sanford Bledsoe, Jr. and Jochen Schacht ** \\ Kresge Hearing Research Institute, Unicersity of Michigan, Ann Arbor, MI 48109, U.S.A.
}

(Received 20 May 1985; accepted 18 July 1985)

\begin{abstract}
Guinea pigs received a bolus of gentamicin ( $10 \mathrm{mM}$ for $5 \mathrm{~min})$ by perilymphatic perfusion which normally led to an irreversible loss of the cochlear microphonic potential (CM). Various experimental conditions that reduced the endolymphatic potential (F.P) were then superimposed on the gentamicin application. Reversible reductions in EP (and, concomitantly, in CM) were induced hy asphyxia $(3 \mathrm{~min})$. intravenous furosemide $(50 \mathrm{mg} / \mathrm{kg}$ ), and perilymphatic perfusion of aminooxyacetic acid (10 $\mathrm{mM}$ ). When the administration of gentamicin was initiated at the time of maximal EP reduction the usual irreversible gentamicin-induced decline of ( $M$ was prevented.

The results indicate that a metabolic process is essential in the expression of gentamicin toxicity. The data are consistent with the inhibition of an energy-dependent transport of the aminoglycoside. Alternatively, the data are also compatible with the hypothesis that entry of gentamicin into hair cells is prevented by a reduction in their transmembrane electrical potential.
\end{abstract}

aminoglycosides, ototoxicity, gentamicin, energy-dependent uptake, transmembrane potential

\section{Introduction}

Based on several lines of evidence, this laboratory has formulated a hypothesis to explain the acute and chronic ototoxic actions of aminoglycosides in the inner ear $[16,20,21]$. In the course of their action, the aminoglycosides appear to occupy at least two different cellular compartments. Perilymphatic perfusions of the guinea pig cochlea with gentamicin reduced the cochlear microphonic potential (CM) with an initial acute phase that was readily reversed by the addition of calcium; this was followed by a second phase insensitive to calcium [23]. Pharmacokinetic data demonstrated two different half-lives of gentamicin in cochlear tissues prior to and after the onset of chronic toxicity [25]. Consistent with these data would be a binding of gentamicin to the external cell surface as a first step (first compartment) and binding to intracellular components such as polyphos-

\footnotetext{
* Present address: Department of Otolaryngology, Kyoto Prefectural University of Medicine, Kyoto, Japan.

** To whom correspondence should be addressed.
}

phoinositides in the second compartment [21.26]. It would have to be postulated that an uptake process transfers the drug from the outside to the inside of the cell. Some aspects of aminoglycoside uptake in the kidney $[1,11]$ have been characterized but more detailed analyses have been carried out in bacteria where two distinct energydependent phases of uptake are documented [10]. There is no information on aminoglycoside uptake mechanisms in the cochlea.

The generation and maintenance of a transmembrane potential across the cytoplasmic membrane is a basic feature of all living cells. This potential and the distribution of ions associated with it play an essential role in membrane associated phenomena such as ionic conductance and transport processes. Recently, evidence has been presented that the magnitude of the transmembrane potential in bacterial cells is a determining factor in aminoglycoside uptake and bactericidal action [9]. Thus, more negative membrane potentials produced greater aminoglycoside uptake and enhanced bactericidal effects. A relationship of the transmembrane potential to aminoglycoside oto- 
toxicity is particularly attractive in view of the selective actions of aminoglycosides on outer hair cells which have been shown to have a more negative membrane potential than inner hair cells [8].

The present study was undertaken to test whether aminoglycoside actions are related to energy-dependent phenomena. The effects of gentamicin in perilymphatic perfusions on $\mathrm{CM}$ were studied under conditions of reduced endolymphatic potentials (EP). A reduction in EP by the experimental manipulations was assumed to be an indicator of reduced energy for the maintenance of transmembrane potentials and of transport processes of cochlear cells.

\section{Materials and Methods}

Experiments were performed on male guinea pigs (Hartley) weighing 250-400 g. Surgical and perilymphatic perfusion techniques were essentially as previously described $[16,17,23]$. An animal with a positive Preyer reflex was anesthetized with sodium pentobarbital ( $20 \mathrm{mg} / \mathrm{kg}$ body wt., i.p.), atropine sulfate $(0.05 \mathrm{mg} / \mathrm{kg}$ body wt., s.c.) and Innovar $(0.5 \mathrm{ml} / \mathrm{kg}$ body wt., i.m. containing 0.4 $\mathrm{mg}$ fentanyl and $20 \mathrm{mg}$ droperidol $/ \mathrm{ml}$ ). Rectal temperature was maintained at $37 \pm 1{ }^{\circ} \mathrm{C}$ with a heating pad and artificial respiration provided through a tracheal cannula.

The EP was measured with a $3 \mathrm{M} \mathrm{KCl}$ microelectrode inserted through the spiral ligament of the basal turn [14]. Perilymphatic perfusions were performed via glass capillaries implanted into the basal turn of scala tympani and scala vestibuli. The perfusion pipettes were placed prior to insertion of the EP recording electrode. The flow of perfusate was initiated after establishing a stable, positive EP. The CM was measured from a recording electrode in the scala tympani perfusion pipette and a reference electrode in the superficial masseter muscle. The $\mathrm{CM}$ was recorded in response to a sound stimulus of white noise, $20-4000 \mathrm{~Hz}$, delivered to the external auditory meatus through an earphone coupled to an ear speculum. The sound intensity was adjusted to approximately 70 $\mathrm{dB}$ SPL to give an initial $\mathrm{CM}$ of $200-400 \mu \mathrm{V}$ (RMS).

Perilymphatic spaces were perfused at a rate of approximately $30 \mu \mathrm{l} / \mathrm{min}$ with artificial perilymph containing $130 \mathrm{mM} \mathrm{NaCl}, 5 \mathrm{mM} \mathrm{KCl}, 1 \mathrm{mM}$ $\mathrm{CaCl}_{2}, 2 \mathrm{mM} \mathrm{MgCl}, 0.1 \mathrm{mM} \mathrm{NaH} \mathrm{PO}_{4}, 10 \mathrm{mM}$ $\mathrm{NaHCO}_{3}, 5 \mathrm{mM}$ glucose and $10 \mathrm{mM}$ Hepes, final $\mathrm{pH}, 7.4$. Gentamicin sulfate was dissolved in the artificial perilymph at a concentration of $10 \mathrm{mM}$ and the $\mathrm{pH}$ adjusted with $\mathrm{NaOH}$. After $\mathrm{CM}$ and EP had stabilized for $30 \mathrm{~min}$ the control perfusate' was switched to the 'experimental perfusate' containing drug. Gentamicin was perfused for $5 \mathrm{~min}$ whereafter perfusion with the control perfusate was resumed. Experiments were usually carried out for 90-120 min but perfusions without drugs could be extended for up to $3 \mathrm{~h}$ without major $(<20 \%)$ loss of CM. Animals with an initial $\mathrm{CM}$ of less than $200 \mu \mathrm{V}$ or with an unstable CM and EP during the control period (loss of $>10 \%$ ) were eliminated from the study. Amino-oxyacetic acid $(10 \mathrm{mM})$ was dissolved in artificial perilymph and the $\mathrm{pH}$ adjusted with $\mathrm{NaOH}$. Furosemide (50 $\mathrm{mg} / \mathrm{kg}$ body weight) was injected over $90 \mathrm{~s}$ intravenously via a catheter in the left jugular vein. Anoxia was induced by shutting off the respirator. Furosemide and aminooxyacetic acid (AOAA) were purchased from Sigma. Gentamicin sulfate was a gift from the Schering Corporation (Bloomfield, $\mathrm{NJ}$ ).

\section{Results}

Gentamicin at a concentration of $10 \mathrm{mM}$ perfused as a bolus through the perilymphatic space for 5 min drastically reduced the microphonic potential but had no effect on the endolymphatic potential (Fig. 1 and Table I). The CM began to decline rapidly within $30 \mathrm{~s}$ after gentamicin entered the cochlea and continued to decline, although after the $5 \mathrm{~min}$ perfusion the perfusate no longer contained the drug. Consistently, a $60 \%$ reduction of $\mathrm{CM}$ was reached after $60 \mathrm{~min}$. This irreversible action of gentamicin on $\mathrm{CM}$ and its lack of effect on EP have been described before $[12,13]$.

Anoxia induced by turning the respirator off produced a rapid decline in EP and CM (Fig. 2). This effect rapidly and completely reversed if the respirator was turned back on after $3 \mathrm{~min}$ (Fig. 2 and Table I) consistent with reports by others [14]. When the perilymphatic space was perfused with 


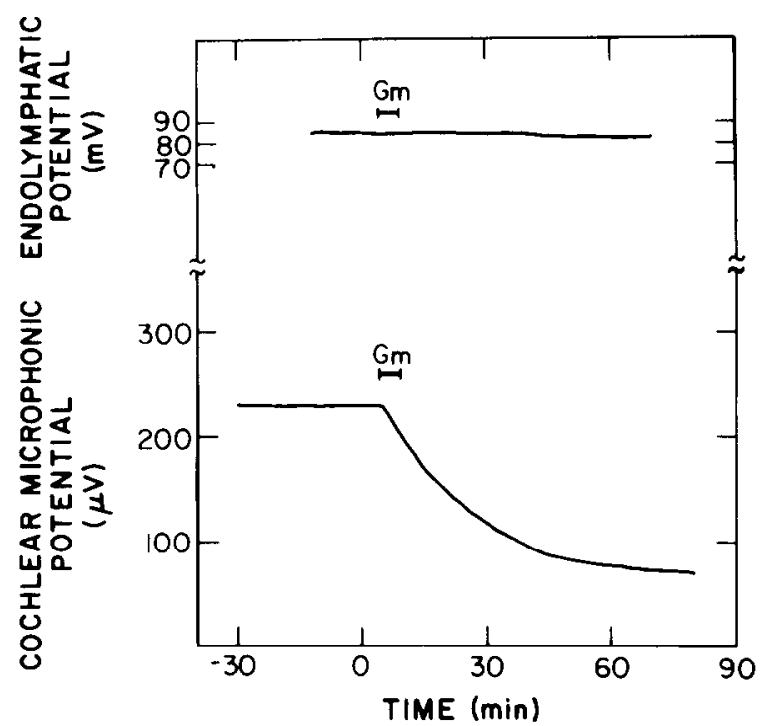

Fig. 1. Time course of gentamicin action on endolymphatic and cochlear microphonic potentials. Techniques for carrying out perilymphatic perfusions and recording EP and $\mathrm{CM}$ were as described in Materials and Methods. Following the control perfusion ('stabilizing period', -30 to $0 \mathrm{~min}$ ), the perfusate
$10 \mathrm{mM}$ gentamicin for $5 \mathrm{~min}$ beginning at a time when EP and CM were suppressed by asphyxia the usual irreversible actions of gentamicin on $\mathrm{CM}$ were prevented (Fig. 2 and Table I). One hour after anoxia plus gentamicin, CM had recovered to $97 \pm 6 \%$ of its pre-drug control value (Table I) whereas one hour after gentamicin alone, CM was $40 \pm 2 \%$ of its pre-drug value (Table I).

Following intravenous injections of a bolus of furosemide $(50 \mathrm{mg} / \mathrm{kg})$, the endolymphatic potentials fell rapidly to near zero values (Fig. 3). The peak suppression of EP and CM occurred in less than $2 \mathrm{~min}$. This was followed by a quick recovery of EP by about $20-30 \mathrm{mV}$, a plateau and then a gradual recovery to pre-injection values (Fig. 3). The CM followed a similar time course of recovery

was changed at the point indicated for $5 \mathrm{~min}$ to experimental perfusate containing $10 \mathrm{mM}$ gentamicin $(\mathrm{Gm})$. Curves are mean values from 4 animals (EP) and 5 animals (CM). Note the lack of effect of gentamicin on the EP.

TABLE I

EFFECT OF DRUG TREATMENTS ON COCHLEAR POTENTIALS

See Figs. $1-4$ for experimental conditions.

A. Endolymphatic potential

\begin{tabular}{|c|c|c|c|c|c|}
\hline Treatment & Control & $\begin{array}{l}\text { Minimum } \\
(\mathrm{mV})\end{array}$ & $\begin{array}{l}\text { Recovered } \\
(\mathrm{mV})\end{array}$ & $\begin{array}{l}\text { Time } \\
\text { (min) }\end{array}$ & $n$ \\
\hline Gentamicin & $80+4$ & - & $78+3$ & 60 & 4 \\
\hline Anoxia & $82 \pm 5$ & $-11 \pm 6$ & $81 \pm 4$ & 18 & 4 \\
\hline Anoxia + Gm & $80 \pm 6$ & $-3 \pm 13$ & $82 \pm 5$ & 18 & 6 \\
\hline Anoxia $/ \mathrm{Gm}$ & & & $80 \pm 6$ & 60 & 6 \\
\hline Furosemide $+\mathrm{Gm}$ & $84 \pm 4$ & $12 \pm 7$ & $72 \pm 5$ & 90 & 2 \\
\hline $\mathrm{AOAA}+\mathrm{Gm}$ & $81 \pm 11$ & $18 \pm 7$ & $16 \pm 3$ & 60 & 4 \\
\hline \multicolumn{6}{|c|}{ B. Cochlear microphonics } \\
\hline \multirow[t]{2}{*}{ Treatment } & & Minimum & Recovered & \multirow{2}{*}{$\begin{array}{l}\text { Time } \\
(\min )\end{array}$} & \multirow[t]{2}{*}{$n$} \\
\hline & & \multicolumn{2}{|c|}{$(\%$ of control $)$} & & \\
\hline Gentamicin & & & $40 \pm 2$ & 60 & 5 \\
\hline Anoxia & & $47 \pm 10$ & $100 \pm 2$ & 18 & 6 \\
\hline Anoxia + Gm & & $46 \pm 11$ & $97 \pm 4$ & 18 & 7 \\
\hline Anoxia + Gm & & & $97 \pm 6$ & 60 & 7 \\
\hline Furosemide & & $44 \pm 11$ & $102 \pm 8$ & 90 & 4 \\
\hline Furosemide $+\mathrm{Gm}$ & & $44 \pm 4$ & $107 \pm 8$ & 90 & 3 \\
\hline AOAA & & $52 \pm 10$ & $72 \pm 7$ & 60 & 5 \\
\hline AOAA -. Gm & & $48 \pm 10$ & $73 \pm 8$ & 60 & 5 \\
\hline $\mathrm{Gm}--$ AOAA & & $47 \pm 4$ & $48 \pm 3$ & 60 & 4 \\
\hline
\end{tabular}

a Time from beginning of treatment to measurement of recovered potential. 


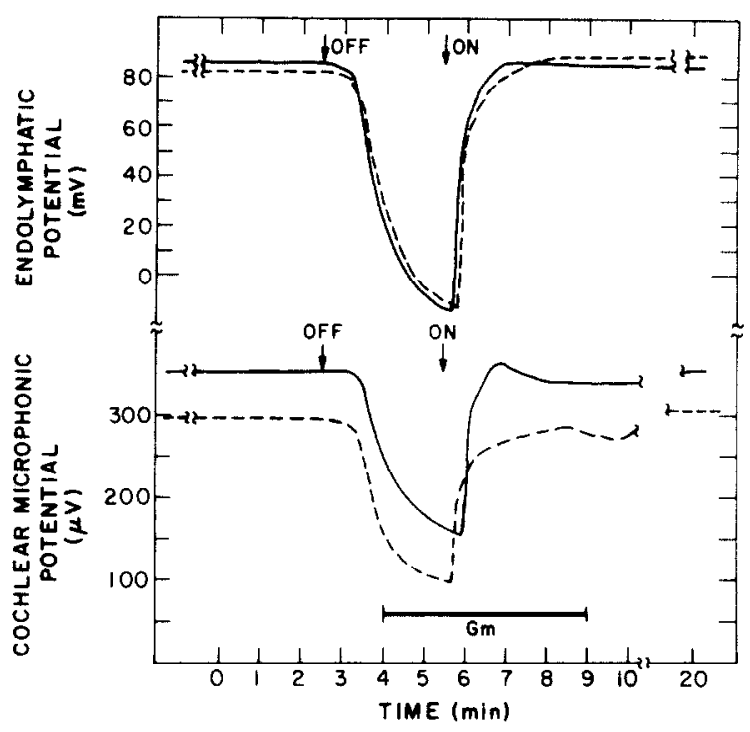

Fig. 2. Prevention of gentamicin-induced suppression of cochlear microphonic potentials during anoxic reduction of the endolymphatic potential. Experimental procedures were carried out as described in Materials and Methods. Following the control perfusion for $30 \mathrm{~min}$ the respirator was turned off at the time indicated by the arrow. $90 \mathrm{~s}$ later the control perfusate was changed to experimental perfusate containing $10 \mathrm{mM}$ gentamicin (GM) for $5 \mathrm{~min}$. Bar indicates time that gentamicin was in the perilymphatic space. After $3 \mathrm{~min}$ of asphyxia the respirator was turned back on. Thus, CM and EP were markedly reduced by anoxia at the time gentamicin entered the cochlea and remained suppressed for at least 2 of the $5 \mathrm{~min}$ of exposure to the drug. $\longrightarrow$, perfusions without gentamicin; - . - perfusions with gentamicin. Note that in contrast to results shown in Fig. 1 the CM recovers to pre-drug values.

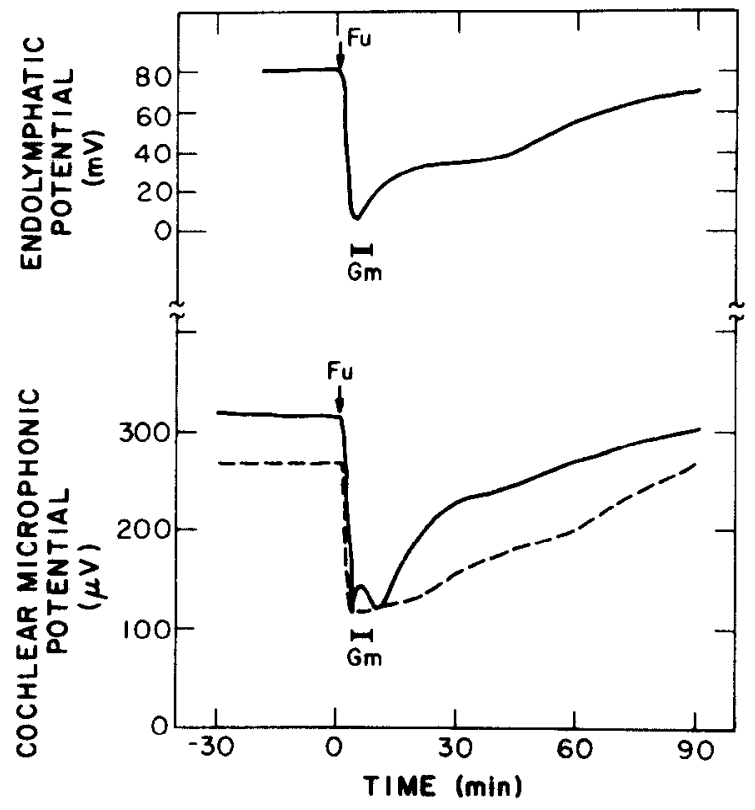

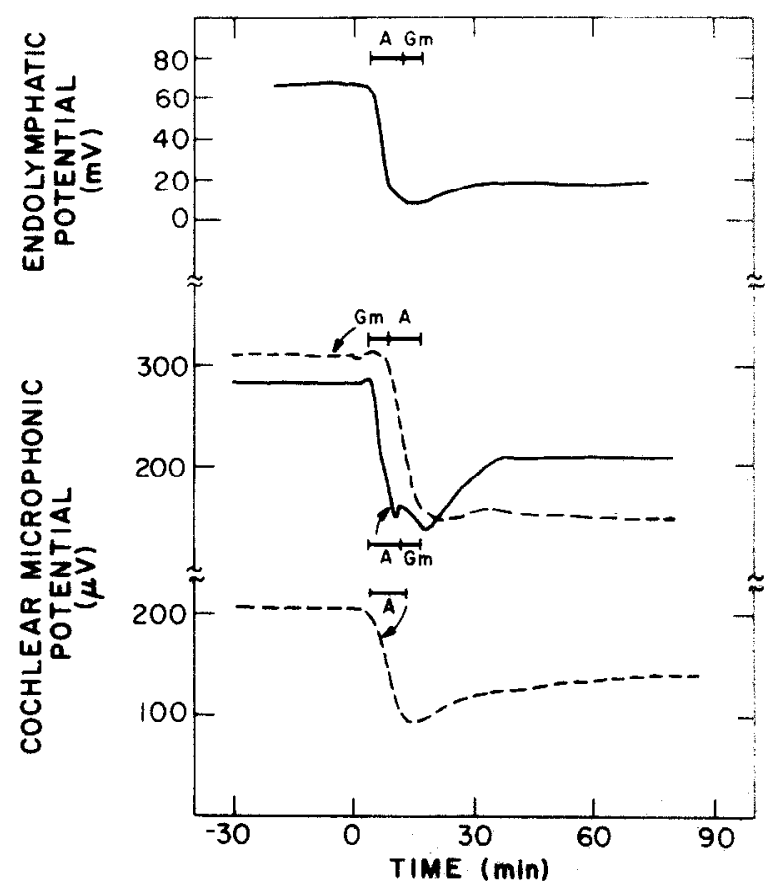

Fig. 4. Prevention of gentamicin-induced suppression of cochlear microphonic potentials during reduction of the endolymphatic potential by aminooxyacetic acid. Experimental procedures were as described in Materials and Methods. Following the control perfusion, drugs were introduced into the perfusate for the time and sequence indicated by the bars: $A$. aminooxyacetic acid $(10 \mathrm{mM})$; $\mathrm{Gm}$, gentamicin $(10 \mathrm{mM})$. Note the contrast in the recovery of $\mathrm{CM}$ depending on the sequence of administration of the two drugs.

and returned to $102 \pm 8 \%$ of its initial value by 90 min (lable I). These results, again, are compatible with previous reports by others [19]. The actions of $10 \mathrm{mM}$ gentamicin were prevented when the $5 \mathrm{~min}$ perfusion of gentamicin was initiated at the time of peak suppression of EP by furosemide (Fig. 3 and Table I). With furosemide plus gentamicin,

Fig. 3. Prevention of gentamicin-induced suppression of cochlear microphonic potentials during reduction of the endolymphatic potential by furosemide. Experimental procedures were carried out as described in Materials and Methods. Following the control perfusion ('stabilizing period', -30 to 0 $\mathrm{min}$ ), furosemide (Fu) was injected intravenously into the left jugular vein as a bolus over $90 \mathrm{~s}$. At the point of maximum CM and EP suppression the control perfusate was changed to experimental perfusate containing $10 \mathrm{mM}$ gentamicin (GM) for $5 \mathrm{~min}$. Bar indicates time that gentamicin was in the perilymphatic space. $\longrightarrow$, perfusion without gentamicin; - . . -, with gentamicin. Again, note that in contrast to results shown in Fig. 1 the $\mathrm{CM}$ recovers to pre-gentamicin values. 
CM had recovered to $107 \pm 8 \%$ of its initial value by $90 \mathrm{~min}$ (Table I).

Perilymphatic perfusion of $10 \mathrm{mM}$ AOAA rapidly suppressed EP and CM (Fig. 4). The effects of AOAA were reversible but required prolonged periods of perfusion with drug-free perfusate: by $60 \mathrm{~min}, \mathrm{CM}$ had only recovered to $72 \pm 7 \%$ of pre-AOAA values (Table I). These effects of AOAA on cochlear potentials are in keeping with reports of others [2,3]. The actions of $10 \mathrm{mM}$ gentamicin on $\mathrm{CM}$ were prevented if the 5 min gentamicin perfusion began at the time of maximal EP and CM suppression (Fig. 4 and Table I) by AOAA. In contrast, if the administration of gentamicin preceded the perfusion of AOAA there was little, if any, recovery of CM after $60 \mathrm{~min}$ when compared to perfusions of gentamicin alone (Table I).

\section{Discussion}

The salient finding is that the expression of gentamicin toxicity requires an active metabolic process. This is the broadest interpretation of the fact that gentamicin toxicity is prevented when the drug is administered during a period of decreased endolymphatic potential. In this context the reduction of E.P is taken as an indicator of interference with energy metabolism in cochlear structures. The question then arises what this active metabolic process is and how it affects the mechanism of aminoglycoside toxicity.

First we may consider the uptake of the drug. In the mechanism of the antibacterial activity of aminoglycosides it is clearly established that an active uptake process precedes the toxic effect of the drug [10] and uptake into the kidney also has an energy-dependent component [1]. For the inner ear such evidence still is lacking but results presented here are compatible with an active drug uptake system in the inner ear. When inhibited by such manipulations as asphyxia, the drug would not penetrate the cells and thus not he toxic.

The nature of the cochlear uptake system cannot be delineated from the present study. A target-specific inhibition of a transport system seems unlikely since such diverse agents as asphyxia. furosemide, and aminooxyacetic acid all produced a similar effect. Rather, since all agents used inhibit metabolism as indicated by the decrease in EP, an interference with the energy supply to such a system may be the common action. Thus, any active carrier-mediated transport or ATP-dependent co-transport of aminoglycosides is compatible with the evidence. If, however, ATP levels remain largely unaffected in the hair cells during the acute phase of furosemide-induced reduction of EP as proposed for the stria vascularis [15] more restraints have to be applied to the model.

An alternative energy-dependent uptake of gentamicin could be driven by the transmembrane potential of the cells as demonstrated in bacteria [9]. The appeal of postulating a potential-related uptake in the inner ear is the apparent correlation between the susceptibility of inner and outer hair cells to aminoglycosides and their potential. Intracellular potentials of cochlear inner hair cells and supporting cells, however, show only small changes during transient asphyxia [4.18]. It would have to be assumed that under the conditions of the experiments the major action of the aminoglycosides is on the apical end of the hair cells: the reduction of the endolymphatic potential would lower the driving force for drug entry into the cells. Pharmacokinetic evidence for the route of access of aminoglycosides to endolymph is not entirely clear [24] and endolymph may not be the major compartment from which these drugs enter the hair cells after systemic injections [25].

While an inhibition of drug uptake seems the most direct explanation for the observed effects other interpretations are possible. For example, an inhibition of metabolism would also affect any metabolism of the drug itself. Drug metabolism may be a crucial determinant in toxicity as in the case of the nephrotoxic actions of the antineoplastic drug. cis-dichlorodiamine platin. The parent compound apparently has lower toxicity than its metabolites [7]. Considering the design of the experiments in this study it would have to be postulated that the initial step in aminoglycoside toxicity is a metabolic transformation and that the metabolite, but not the parent compound, will penetrate the cell to cause permanent damage. It is, however, generally assumed that aminoglycosides are not metabolized so that this interpretation appears less likely.

An apparent paradox in the current results is 
the fact that the acute combination of two potentially ototoxic drugs results in reduced ototoxicity rather than a potentiation as observed when the same drugs are administered systemically. A potentiation has been reported for aminoglycosides in combination with both, furosemide [5] as well as aminooxyacetic acid [6]. Several reasons may account for this lack of interaction: gentamicin is given here by perilymphatic perfusions possibly eliminating the site of interaction; or, that in this acute combination neither drug has sufficient time to cause the effect that would lead to potentiation.

The postulate of an active uptake process for aminoglycosides in the cochlea fits well into the model we have previously proposed for their ototoxicity since phosphoinositides are considered to be present in the inner (cytoplasmic) surface of the membrane. The drug would first bind to negatively charged sites on the external plasma membrane such as acidic phospholipids. This action, antagonized by calcium, would account for the acute and reversible effects of the aminoglycosides. Following the uptake into the cells, the drugs bind to phosphoinositides, inhibit their function and disrupt membrane structure. The susceptibility of a tissue to aminoglycosides would then depend on both the presence of an uptake system and the presence of intracellular sites of action, most importantly, phosphoinositides.

The precise nature of the energy-dependent process involved in aminoglycoside toxicity remains to be elucidated. Both hypotheses raised, active carrier-mediated transport or transport by membrane potential, are amenable to further testing in vivo and in vitro. Our finding already points to the complexity of the aminoglycoside action in the inner ear and shows novel parallels between the cochlear and the renal and bacterial handling of the drug.

\section{Acknowledgements}

This research was supported by a research grant NS-13792 from the National Institutes of Health. A preliminary account of these findings was previously reported [22].

\section{References}

1 Bennett, W.M., Plamp, C.E.. Elliot, W.C., Parker, R.A. and Porter, G.A. (1982): Effects of basic amino acids and aminoglycosides on $\mathrm{H}-3$ gentamicin uptake in cortical slices of rat and human kidney. J. Lab. Clin. Med. 99, 156-162.

2 Bobbin, R.P. and Gondra, M. (1973): Effect of intravenous aminooxyacetic acid on guinea pig cochlear potentials. Neuropharmacology 12, 1005-1007.

3 Bobbin, R.P. and Guth, R.S. (1970): Evidence that gamma-aminobutyric acid is not the inhibitory transmitter at the crossed olivocochlear nerve-hair cell junction. Neuropharmacology 9, 567-574.

4 Brown, M.C., Nuttall, A.L., Masta, R.I. and Lawrence, M. (1983): Cochlear inner hair cells: Effects of transient asphyxia on intracellular potentials. Hearing Res. 9, $131-144$.

5 Brummett, R.E. (1981): Effects of antibiotic-diuretic interactions in the guinea pig model of ototoxicity. Rev. Infect. Dis. 3, S216-S223.

6 Bryant, G.M., Cronin-Schreiber, R., Alexander, A., Norris, C.H., Quine, D.B. and Guth, P.S. (1984): The potentiation of ototoxicity when aminooxyacetic acid and kanamycin are co-administered. Hearing Res. 15, 173-178.

7 Daley-Yates, P.T. and McBrien, D.C.H. (1984): Cisplatin metabolites in plasma, a study of their pharmacokinetics and importance in the nephrotoxic and antitumor activity of cisplatin. Biochem. Pharmacol. 33, 3063-3070.

8 Dallos P., Santos-Sacchi, J. and Flock, A. (1982): Intracellular recordings from cochlear outer hair cells. Science 218 , $582-584$.

9 Eisenberg, E.S., Mandel, L.J., Kaback, H.R. and Miller, M.H. (1984): Quantitative association between electrical potential across the cytoplasmic membrane and early gentamicin uptake and killing in Staphylococcus uureus. J. Bacteriol. 157, 863-867.

10 Hancock, R.E.W. (1981): Aminoglycoside uptake and mode of action-with special reference to streptomycin and gentamicin. I. Antagonists and mutants. Antimicrob. Chemother. 8, 249-276.

11 Josepovitz, C., Pastoriza-Munoz, E., Timmerman, D., Scott, M., Feldman, S. and Koloyanides, G.J. (1982): Inhibition of gentamicin uptake in rat renal cortex in vivo by aminoglycosides and organic polycations. J. Pharm. Exp. Ther. 223, 314-321.

12 Kommune, S. and Snow, J.B. (1981): Ototoxicity of kanamycin sulfate and the barriers in the inner ear. Otolaryngol. Head Neck Surg. 89, 1013-1018.

13 Konishi, T. (1979): Effects of local application of ototoxic antibiotics on cochlear potentials in guinea pigs. Acta Otolaryngol. 88, 41-46.

14 Konishi, T., Butler, R.A. and Fernandez, C. (1961): Effect of anoxia on cochlear potentials. J. Acoust. Soc. Am. 33. 349-356.

15 Kusaskari, J., Ise, I., Comegys, T.H., Thalmann, I. and Thalmann, R. (1978): Effect of ethacrynic acid, furosemide, and ouabain upon the endolymphatic potential and upon 
high energy phosphates of the stria vascularis. Laryngoscope 88, 12-37.

16 Lodhi, S., Weiner, N.D., Mechigian, I. and Schacht, J. (1980): Ototoxicity of aminoglycosides correlated with their action on monomolecular films of polyphosphoinositides. Biochem. Pharmacol. 29, 597-601.

17 Nuttall, A.L., LaRouere, M.J. and Lawrence, M. (1982): Acute perilymphatic perfusion of the guinea pig cochlea. Hearing Res. 6, 207-221.

18 Nuttall, A.L. and Lawrence. M. (1979): Intracellular potential changes of Corti's organ with anoxia. Arch. Otolaryngol. 105. 574-578.

19 Rybak. L.P. and Morizono, T. (1982): Effect of furosemide upon endolymph potassium concentration. Hearing Res. 7 , $223-231$.

20 Schacht, J. (1985): Molecular mechanisms of aminoglycoside toxicity. Abstr. Assoc. Res. Otolaryngol. 8. 68.

21 Schacht, J., Wang, B.M. and Weiner, N.D. (1983): Aminoglycoside-cell receptor interactions: Implications for toxicity and in-vitro models. Proc. 13th Int. Congr. Chemother, 105, 39-44.
22 Takada, A., Bledsoe, S. and Schacht, J. (1984): Membrane potential - A factor in aminoglycoside toxicity? Abstr. Assoc. Res. Otolaryngol. 7, 109.

23 Takada, A. and Schacht, J. (1982): Calcium antagonism and reversibility of gentamicin-induced loss of cochlear microphonics in the guinea pig. Hearing Res. 8, 179-186.

24 Tran Ba Huy, P., Manuel, C., Meulemans, A., Sterkers, O. and Amiel, C. (1981): Pharmacokinetics of gentamicin in perilymph and endolymph of the rat as determined by radioimmunoassay. J. Infect. Dis. 143, 476-486.

25 Tran Ba Huy, P. and Schacht, J. (1983): Pharmacokinetics of gentamicin in the tissues of the inner ear of the rat. Abstr. Assoc. Res. Otolaryngol. 6. 52.

26 Wang. B.M., Weiner, N.D., Takada. A. and Schacht, J. (1984): Characterization of aminoglycoside-lipid interactions and development of a refined model for ototoxicity testing. Biochem. Pharmacol. 33, 3257-3262. 